\title{
Research of injuries of passengers in city buses as a consequence of non-collision effects
}

\author{
Aleksandar Zunjic ${ }^{\mathrm{a},}{ }^{*}$, Vladimir Sremcevic ${ }^{\mathrm{b}}$, Vera Zeravcic Sijacki and Ana Sijacki ${ }^{\mathrm{c}}$ \\ ${ }^{a}$ University of Belgrade, Faculty of Mechanical Engineering, Kraljice Marije 16, 11000 Belgrade, Serbia \\ ${ }^{\mathrm{b}}$ Muzicka skola Mokranjac, 11000 Belgrade, Serbia \\ ${ }^{c}$ University of Belgrade, School of Medicine, Dr Subotica 8, 11000 Belgrade, Serbia
}

\begin{abstract}
In this study, a research of injuries of passengers in city buses is presented, which are not a consequence of collision of buses with other objects. The number of injured passengers in the territory of Belgrade was registered, during three consecutive years. Most frequently injured body part was the head, while women over the age of 60 are the most vulnerable population of passengers. The most often reason for the appearance of injuries was the effect of acceleration. Also, it is pointed out to the importance of consideration of the problem of multiple injuries. These injuries are more complex than the individual ones, and they may indicate to the existence of greater omissions in the design of the interior of the bus. Proposals for certain system solutions, as well as some recommendations for designing are given, which can improve the safety of passengers who use the city bus as a means of transportation.
\end{abstract}

Keywords: city bus transport, passenger injuries, bus interior design

\section{Introduction}

In large urban areas, bus transportation uses daily a large number of passengers. Accordingly, of particular importance for society as a whole is to ensure a safe and comfortable transportation of passengers, who use buses as a primary means of transportation. However, especially in urban areas, which include over one million inhabitants, the problem of frequent injuring of passengers who use buses to come to places where they work (or perform a particular activity) has been noticed.

There are two basic ways, which can lead to appearance of injuries in passengers. The first way is a consequence of the collision factor, when the bus hit the other stationary or non stationary object. Bus designers tend to achieve the necessary safety by designing the outer structure of adequate strength, when we consider the problem of contact of bus with another object. Another way that may bring to the pas- senger injuries is the result of effects of non-collision factor, i.e. when the bus does not hit another object. These injuries can have many causes.

In other words, non-collision effects are those effects that are not a result of the collision of a bus with other objects. Non-collision effects are primarily the consequence of design of the bus interior, because in this case, there is not a large external force that arises from another object, which acts on the bus and passengers. From the standpoint of the bus designing, injuries that arise due to non-collision effects primarily are caused by inadequate design of the bus interior, because we can consider that the small forces should not lead to the serious or fatal injuries.

Injuries sustained in the buses, caused by the collision effect much more have attracted the public attention. Probably, for this reason, far more attention has directed to the design of external bus components from the safety aspect, by designers of buses for public transport of passengers. A number of researches

\footnotetext{
*Address for correspondence: Aleksandar Zunjic, Ph.D., Assoc. Prof., Department of Industrial Engineering, Faculty of Mechanical Engineering, University of Belgrade, Kraljice Marije 16, 11000 Belgrade, Serbia, Tel.: +381642537486; E-mail: azunjic@mas.bg.ac.rs
} 
$[1-5,7]$ drew attention to the fact that injuries of the passengers in the buses due to the effect of noncollision factor can be serious and numerous, as well as due to the effect of the collision factor. Wahlberg [8-9] points out that even at low-speed of buses, serious injuries may occur. It is believed that older persons are particularly vulnerable when they use public bus transportation [6].

Belgrade (capital of Serbia) is a city with about $1,500,000$ inhabitants, where vehicles of public transport daily uses about 1,000,000 inhabitants. There is no a scientific study that was previously performed, regarding injuries of passengers in buses for public transport in Belgrade. With that in mind, as well as the fact that the bus transportation of passengers in Belgrade is widely used, and the fact that it is known that such injuries exist, the aim of this study was to determine the number and type of injuries of passengers, which use this mode of transport. In this way, we can gain a realistic picture of the dimension of this problem. In addition, based on the identification of types and modes of injury, we can gain insight into the failures that may exist when we consider the design of the interior of buses, which is intended for the public transport. Such an analysis leads to the proposals for redesigning of the interior of these types of buses.

Given the above, the subject of this paper are injuries of the passengers, which arise as a consequence of effects of non-collision factor, since we consider that this factor can provide an answer regarding mistakes in the design of the interior of buses more reliable than the collision factor. This is because the common practice is that injuries, which appear in the collision of a bus and other object, are primarily connected with the solution for a bus construction, as well as with the force that arises in the collision.

\section{Method}

In connection with the collection of data on injuries that have occurred on buses that are in use for urban transport of passengers, it is necessary to point out that in Belgrade, there was no organized, systematic approach to collecting these types of data. Taking into account several possible sources of data, after the insight into their state, we chose the archives of the Emergency Center in the Clinical Center of Belgrade, as the most reliable source of information. Data were collected through the extraction of records concerning injuries that occur in the buses for public transport, based on the documentation of all injuries, which are conducted for all patients, whose injuries are treated in the Clinical Center of Belgrade. This documentation is in paper form, so the data collection lasted several months. Data regarding injuries of passenger arising from the non-collision circumstances for 2008, 2009 and 2010 were collected.

All the injuries of passengers were classified into three groups, slight, serious and fatal. The same classification of injuries was used in the paper of Kirk, Grant and Bird [5]. Slight injury means any form of medical treatment or attention due to injuries, such as bruising, minor sprains and contusions, cuts that are not severe, as well as a slight shock that requires attention. Serious injury involves obligatory medical treatment in a medical institution due to injuries and conditions such as fractures, severe cuts and lacerations, internal injury, crushing, concussion, as well as severe general shock. This type of injury implies that the fatal outcome of the patient may occur after 30 or more days after the accident, from injuries sustained in that accident. Fatal injury involves those injuries where death occurs in less than 30 days, as a result of the accident. A similar classification of injuries is used for the practical needs by insurance companies in Serbia, in order to compensate for the loss of patients due to injury.

\section{Results}

In order of getting a clearer picture of the extent and type of injuries, it is necessary to present separately individual injury of passengers, from multiple injuries of passengers. Multiple injuries are more complex than the individual injuries, recovery from such injuries often last longer, or they lead to greater exhaustion of the organism as a whole. In addition, they indicate to the existence of a potentially large number of failures in designing of a bus.

Types of injuries will be presented according to the years of their occurrence. In this way, we can gain insight whether increases the number of injuries, decreases or stays at approximately the same level over time. Figure 1 shows individual injuries of passengers in 2008, which occurred on buses for public transport of passengers, within the territory of Belgrade. Darker colored columns relate to slight injuries, whereas lighter colored columns show serious injuries. 


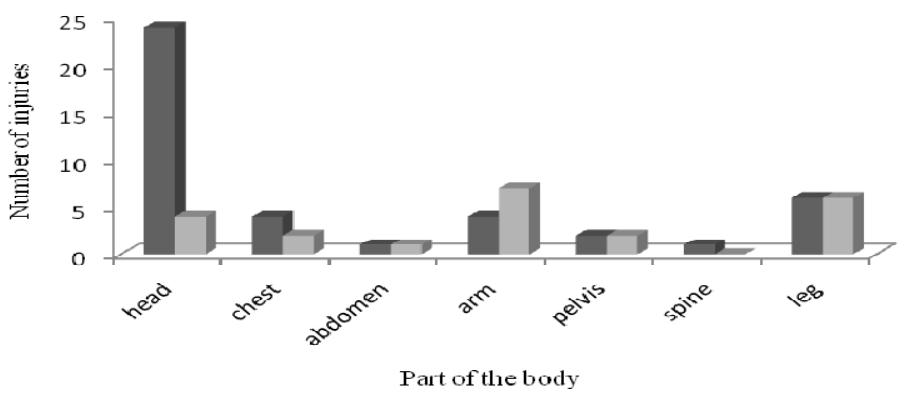

Fig. 1. The number of passengers with individual injuries in 2008 , which occurred in city buses due to the non-collision effects.

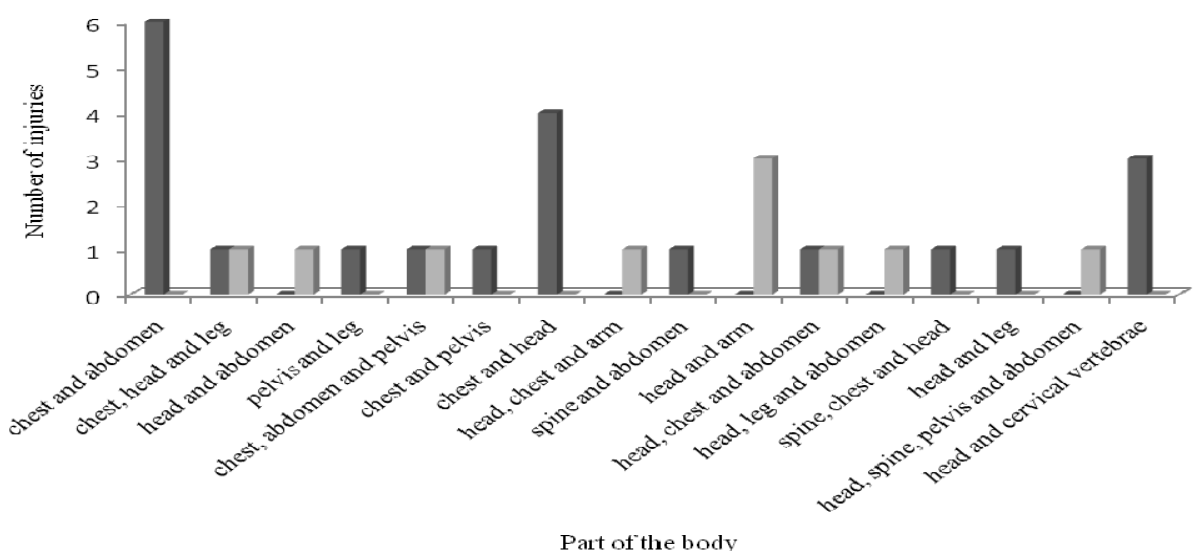

Fig. 2. The number of passengers with multiple injuries in 2008 , which occurred in city buses due to the non-collision effects.

In 2008, due to the non-collision effect, 95 passengers were injured in total, 65 of them were females and 30 males. Of the total number of injured persons, $52.6 \%$ were older than 60 years. Among them is $70 \%$ of women and $30 \%$ of men. Figure 2 shows the multiple injuries of passengers in 2008, which occurred in buses for public transport of passengers in Belgrade.

The total number of injuries (single and multiple) equals 137 . Of the total number of injuries, $35.76 \%$ were serious body injuries. There were not lethal outcomes. Part of the body with most injuries was the head $(35.04 \%)$. Table 1 provides an overview of percentage representation of injuries of certain body parts, taking into account the severity of the injuries of passengers, who were transported in city buses in Belgrade. This table includes individual and multiple injuries.
Table 1

Percentage representation of injured body parts in relation to the total number of injuries that have occurred in city buses in 2008 , due to the non-collision effects.

\begin{tabular}{lll}
\hline Body part & Severity of the injury & Percent (\%) \\
\hline head & slight & 25.547 \\
\cline { 2 - 3 } & serious & 9.489 \\
\hline \multirow{2}{*}{$\begin{array}{l}\text { cervical verte- } \\
\text { brae }\end{array}$} & slight & 2.189 \\
\cline { 2 - 3 } chest & serious & 0 \\
\hline \multirow{2}{*}{ spine } & slight & 13.868 \\
\cline { 2 - 3 } & serious & 4.379 \\
\hline \multirow{2}{*}{ abdomen } & slight & 2.189 \\
\cline { 2 - 3 } & serious & 0.729 \\
\hline \multirow{2}{*}{ arm } & slight & 7.299 \\
\cline { 2 - 3 } & serious & 4.379 \\
\hline pelvis & slight & 2.919 \\
\cline { 2 - 3 } & serious & 8.029 \\
\hline leg & slight & 3.649 \\
\cline { 2 - 3 } & serious & 2.919 \\
\hline
\end{tabular}




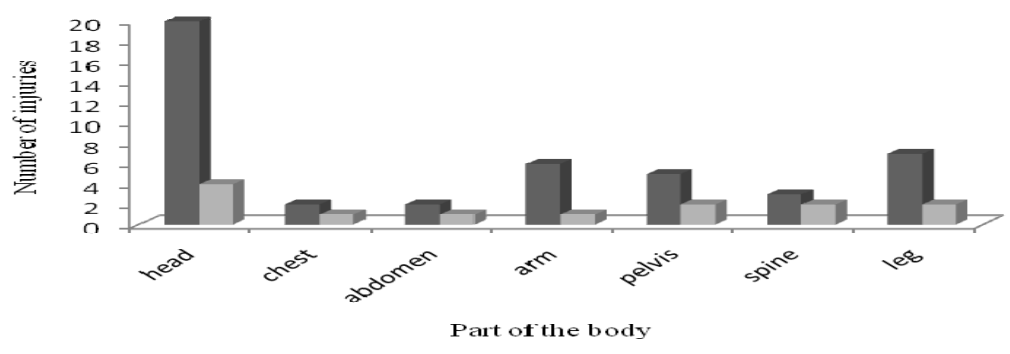

Fig. 3. The number of passengers with individual injuries in 2009 , which occurred in city buses due to the non-collision effects.

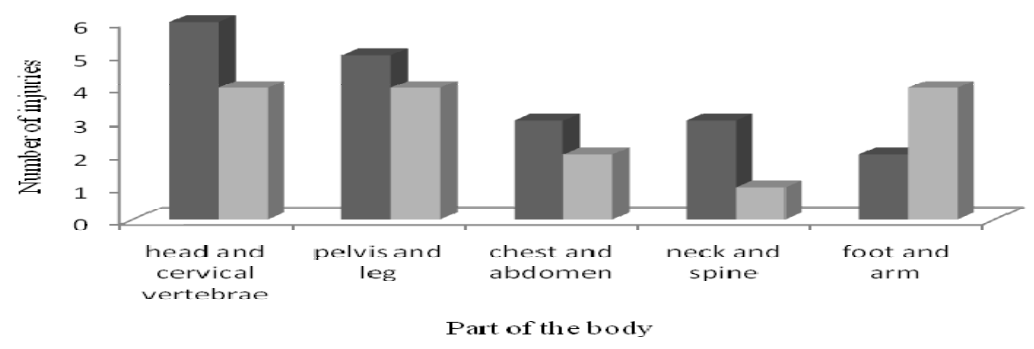

Fig. 4. The number of passengers with multiple injuries in 2009 , which occurred in city buses due to the non-collision effects.

Figure 3 shows individual injuries of passengers in 2009, which occurred on buses for public transport of passengers, within the territory of Belgrade. The figure shows parts of the body that are injured. Considering the type of injury, number of injuries corresponds to the number of individually injured passengers.

In 2009, due to the non-collision effect, 92 passengers were injured in total, 62 of them were females and 30 males. Of the total number of injured persons, $48.9 \%$ were older than 60 years. Among them is $66.7 \%$ of women and $33.3 \%$ of men. Figure 4 shows the multiple injuries of passengers in 2009, which occurred in buses for public transport of passengers in Belgrade.

The total number of injuries (single and multiple) equals 126. Of the total number of injuries, $34.1 \%$ were serious body injuries. There were not lethal outcomes. Part of the body with most injuries was the head $(26.98 \%)$. Table 2 provides an overview of percentage representation of injuries of certain body parts, taking into account the severity of the injuries of passengers, who were transported in city buses in Belgrade. This table includes individual and multiple injuries.
Table 2

Percentage representation of injured body parts in relation to the total number of injuries that have occurred in city buses in 2009 , due to the non-collision effects.

\begin{tabular}{lll}
\hline Body part & Severity of the injury & Percent (\%) \\
\hline head & slight & 20.634 \\
\cline { 2 - 3 } & serious & 6.349 \\
\hline cervical verte- & slight & 4.761 \\
\cline { 2 - 3 } brae & serious & 3.174 \\
\hline chest & slight & 3.968 \\
\cline { 2 - 3 } & serious & 2.38 \\
\hline \multirow{2}{*}{ spine } & slight & 4.761 \\
\cline { 2 - 3 } & serious & 2.38 \\
\hline abdomen & slight & 3.968 \\
\cline { 2 - 3 } & serious & 2.38 \\
\hline arm & slight & 6.349 \\
\cline { 2 - 3 } & serious & 3.968 \\
\hline pelvis & slight & 7.936 \\
\cline { 2 - 3 } & serious & 4.761 \\
\hline \multirow{2}{*}{ leg } & slight & 9.523 \\
\cline { 2 - 3 } & serious & 4.761 \\
\hline foot & slight & 1.587 \\
\cline { 2 - 3 } & serious & 3.174 \\
\hline neck & slight & 2.38 \\
\cline { 2 - 3 } & serious & 0.793 \\
\hline
\end{tabular}




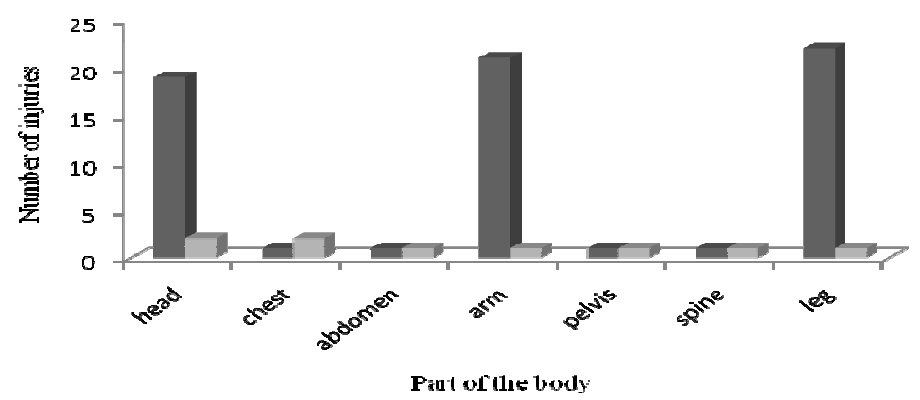

Fig. 5. The number of passengers with individual injuries in 2010, which occurred in city buses due to the non-collision effects.

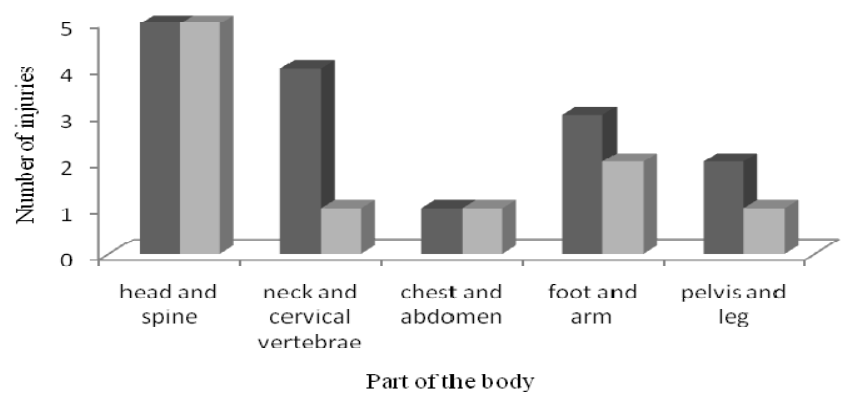

Fig. 6. The number of passengers with multiple injuries in 2010, which occurred in city buses due to the non-collision effects.

Figure 5 shows individual injuries of passengers in 2010, which occurred on buses for public transport of passengers, within the territory of Belgrade. The figure shows parts of the body that are injured. Considering the type of injury, number of injuries corresponds to the number of individually injured passengers.

In 2010, due to the non-collision effect, 100 passengers were injured in total, 57 of them were females and 43 males. Of the total number of injured persons, $49 \%$ were older than 60 years. Among them is $63 \%$ of women and $37 \%$ of men. Figure 6 shows the multiple injuries of passengers in 2010, which occurred in buses for public transport of passengers in Belgrade.

The total number of injuries (single and multiple) equals 125 . Of the total number of injuries, $23.2 \%$ were serious body injuries. There were not lethal outcomes. Part of the body with most injuries was the head $(24.8 \%)$. Table 3 provides an overview of percentage representation of injuries of certain body parts, taking into account the severity of the injuries of passengers, who were transported in city buses in Belgrade. This table includes individual and multiple injuries.
Table 3

Percentage representation of injured body parts in relation to the total number of injuries that have occurred in city buses in 2010 due to the non-collision effects.

\begin{tabular}{|c|c|c|}
\hline Body part & Severity of the injury & Percent (\%) \\
\hline \multirow[t]{2}{*}{ head } & slight & 19.2 \\
\hline & serious & 5.6 \\
\hline \multirow{2}{*}{$\begin{array}{l}\text { cervical verte- } \\
\text { brae }\end{array}$} & slight & 3.2 \\
\hline & serious & 0.8 \\
\hline \multirow[t]{2}{*}{ chest } & slight & 1.6 \\
\hline & serious & 2.4 \\
\hline \multirow[t]{2}{*}{ spine } & slight & 4.8 \\
\hline & serious & 4.8 \\
\hline \multirow[t]{2}{*}{ abdomen } & slight & 1.6 \\
\hline & serious & 1.6 \\
\hline \multirow[t]{2}{*}{ arm } & slight & 19.2 \\
\hline & serious & 2.4 \\
\hline \multirow[t]{2}{*}{ pelvis } & slight & 2.4 \\
\hline & serious & 1.6 \\
\hline \multirow[t]{2}{*}{ leg } & slight & 19.2 \\
\hline & serious & 1.6 \\
\hline \multirow[t]{2}{*}{ foot } & slight & 2.4 \\
\hline & serious & 1.6 \\
\hline \multirow[t]{2}{*}{ neck } & slight & 3.2 \\
\hline & serious & 0.8 \\
\hline
\end{tabular}


Regarding the cause of the injuries, it can be distinguished several basic effects. These are: the acceleration or deceleration of buses, boarding and disembarking from a bus, unsafe interior, and other. Table 4 shows the ratio of the number of injured passengers and the causes that led to the injuries. Injuries are classified according to their year of origin and relates to buses for public transport of passengers within the territory of Belgrade. In 2008, 2009 and 2010, most of the injuries appeared due to the effect of bus acceleration, respectively $54.7 \%, 54.34 \%$ and $44 \%$.

This classification of effects was conducted based on data available from the books of protocols of the Clinical Center in Belgrade. The way of appearance of injuries in these books sometimes is not sufficiently detailed or clearly described, so that the table lists the primary effect which led to the injury. Other injuries primarily involve the injuries that occurred under unclear circumstances. This means that the injured person was not aware how he suffered an injury, or due to different circumstances could not describe how the injury occurred at the time of its recording, or omission was made in the management of such records. Besides the aforementioned, the other injuries include injuries that have occurred due to improper behavior of passengers in the vehicle, in the sense of safety. For example, the passenger was transported in a standing position, while both his hands were busy by holding the baggage.

Table 4

Number of injuries in city buses, depending on the non-collision effects.

\begin{tabular}{llll}
\hline \multirow{2}{*}{ Effects } & \multicolumn{2}{l}{$\begin{array}{l}\text { Number of injured passen- } \\
\text { gers }\end{array}$} \\
\cline { 2 - 4 } & 2008 & 2009 & 2010 \\
\hline acceleration /deceleration & 52 & 50 & 44 \\
\hline boarding / disembarking & 29 & 27 & 25 \\
\hline unsafe interior & & & \\
\hline other & 4 & 6 & 11 \\
\hline
\end{tabular}

Among these effects, there is certain interdependence, when considering the manner in which passengers are injured. This means that it is possible some combination of two effects, which together lead to an injury. For example, as a result of the acceleration effect, the passenger could make contact with the part of the bus and thus suffers an injury. Similarly, when entering or exiting the bus, a passenger could also get an injury due to a contact with a part of the interior. However, mentioned protocols did not provide enough reliable data, on the basis of which we would be able to classify the combined influence of these effects.

\section{Discussion}

Taking into account the results during the three observed years, the nearly constant ratio of the number of injured persons and their structure is noticed. People who are most vulnerable to injuries belong to the population over 60 years. Women over 60 years of age are the most vulnerable population of travelers. Most often injured body part is the head.

Effects that cause the injuries were similar to those that are quoted in the papers of authors from other countries, who have considered this issue. In this regard, it is necessary to consider how and why these injuries occur. In other words, it is necessary to determine how the identified non-collision effects have an impact on the occurrence of injury of passengers.

This study has shown that injuries most frequently occur due to changes in acceleration of the bus. Unexpected changes in the flow of traffic often force drivers on suddenly braking. As a result, passenger who was unable to maintain the balance continues with movement, which may end up with an undesired contact of a passenger with a part of the interior of a bus, with other passengers, or with a fall. Passengers who are particularly vulnerable to this type of injury are those who did not hold the handrail in the moment when braking began, as well as people who do not possess sufficient physical strength to resist when there is a great force of inertia, such are elderly passengers, or children. Sudden acceleration of a bus, especially from a state of a standstill, which is caused by the certain traffic situation or by the effort of the driver to respond to the prescribed timetable, can also lead to inadvertent movement of passengers in the vehicle, which ends with their contact with an object inside the bus. Relative to the maintenance of equilibrium position of the body, particularly dangerous is rectilinear movement of a bus, which begins with sudden acceleration and immediately after that ends with sudden deceleration. In such situations, in the short time interval a passenger faces with two forces of inertia of opposite directions. The second inertial 
force hinders the establishment of equilibrium after the action of the first inertial force.

As it is known, the change of the acceleration does not occur only due to changes in the speed, but also due to changes in the direction of movement. Every swerving of a bus aside, as for example due to the tendency of a driver to avoid an unexpected obstacle, due to cornering or entering the side street at a high speed, as well as due to a sharp turn to the bus station that is placed laterally in relation to the mainstream of traffic, can lead to the loss of balance of passengers. This movement of a bus is dangerous not only for elderly people and children, but also for adults who possess enough physical strength to resist to the intensity of acting force. Change of direction of the force leads to the creation of a moment, and conditionally to the rotational movement of passengers. This rotational motion becomes especially apparent when a passenger holds a vertically mounted handrail. Any such rotational movement of a passenger can lead to his injury.

Injuries due to the entry and exit of buses are usually associated with tripping and slipping of passengers on the stairs. Tripping may occur for several reasons. One reason is a wrong estimation of the height of stairs. Weaker mobility of muscles and joints in older people may also be a cause of tripping while moving on the stairs. In the case of a crowd on the bus (especially in terms when people going to work or returning from work), a large number of people were concentrated in the area around the door. An attempt of boarding or disembarking from the bus in such a situation is often associated with "wriggling" through the crowd. Such an unusual movement may also be the cause of loss of balance, which ends with an undesired contact with an object. Insufficient lighting in the bus can also reduce visibility and location of stairs, and leads to the inappropriate movement of passengers. Metal strips on the edges of stairs in the form of small bumps can also cause tripping or slipping. Slipping on the stairs can be expedited by the presence of snow, the traces of ice (in winter months), fluid, leaves or paper materials. Due to the prolonged use of stairs and the effects of friction in the contact with shoes, slightly embossed surface of stairs becomes smooth and slippery, thereby increasing the probability of slipping.

Unsafe bus interior implies design solutions that possess a certain function, but whose application leads to potentially hazardous situations and endangering the security of passengers. This category also includes specific solutions that are not functional from the human aspect. One of the main factors in this category is the unavailability of handrails. It is a very common situation for the people of lower growth that they are not able to reach the handrail, especially when the bus is crowded. Sudden changes in acceleration of the bus in such a situation easily lead to loss of balance of passengers, with the possibility of injuring.

Public transportation in Belgrade provides "GSP Beograd" company. The company in its fleet has 845 buses, of the average age of 8.9 years. The vast majority of the buses are produced by the "Ikarbus" company. There is a total of 28 models of buses that are used to transport passengers in Belgrade. The differences between these models are often minimal when viewed the interior of buses. One of the important factors of a bus interior, which influence safety of passengers is the existence of absorbing coating on the handrails, which are placed at the top of the back of a chair. These coatings prevent the hitting of passengers who are sitting, into the solid material of handrails on the seats in front, in the event of sudden braking. It was found that the models of buses IK103, IK-202, IK-201, MAN SG 313, FAP 537, as well as some minibuses that are used for transport of passengers in Belgrade do not have this coating.

The existence of larger inclination of the floor surfaces of buses is also a factor that can influence the reduction of safety. This factor is additionally dangerous, when it is coupled with the presence of materials, which contribute to the increasing of the slipperiness of surfaces. Larger slopes on surfaces of buses were observed in models IK-103, IK-112N and IK-218N.

The presence of space inside the bus that is designed to accommodate disabled persons is one of the crucial factors, which affects the safety of transportation of these persons. It was noticed that the models of buses IK-103, IK-202, IK-201, MAN SG 313, FAP 537 and minibuses that are used for transport of passengers in Belgrade does not possess the space that provides to accommodation of persons with disabilities.

Low-floor buses make easier entry and exit of persons with disabilities and older people into the vehicles. GSP Belgrade owns 100 low-floor buses, which are released into circulation in 2008. This means that 745 vehicles do not meet this criterion. Of particular importance is the compatibility of level of low-floor buses with a height of sidewalks. Currently, at the majority of bus stops, this condition is not met. However, in recent times efforts are underway to overcome this problem. 


\section{Conclusion}

Based on the results of the research, one can notice almost constant number of passengers injured in Belgrade, on buses for public transportation during the three observed years. This is a significant fact, because it indicates that there were no other or additional effects in relation to the identified, which could cause a different level of injuries in urban buses. In addition, the percentage of injured people is not high, compared with cities in some other countries. For this situation is largely responsible the quality of the organization of Belgrade bus transportation. A significant part of the urban area is covered with special traffic lines, which are only available for buses and taxis. As a result, there is less interference of buses with other vehicles. This is probably the reason why there were no deaths, which are recorded in some other urban areas $[1,3,5]$.

Separate monitoring and determining the level of individual and multiple injuries is of particular importance. Multiple injuries are more complex than a single injury, even when there are only slight injuries. The existence of multiple injuries indicates the existence of the greater number of effects on the body of passengers that come from different objects, or to the existence of a very unsafe object, whose presence may cause greater number of injuries. In the future additional attention should be given to the analysis and detection of such injuries.

Based on the results, it was found that the injuries sustained due to the effect of acceleration are most frequent. To reduce the number of injuries, it is necessary further to educate and warn drivers of the buses. In this regard, it is possible to find determined system solutions. Existing laws on the safety of traffic does not restrict movement of vehicles in curves. There is a huge difference from the aspect of safety, between the vehicle when cornering in winter conditions with a maximum permitted speed and a movement along a straight road in summer conditions with the same speed. However, existing laws on the safety of traffic between these movements of vehicles do not make a special distinction, which is the omission. Finding a solution from this aspect can further improve the safety of passengers, who use the bus as a means of transport.

Designers should pay special attention to the kind and quality of materials, which are incorporated in the interior of the bus. In this regard, it should be avoided the use of hardly deformable materials, such as metal or wood. Instead of them, the use of plastics, rubber and other synthetic materials can be recommended. Coating of solid material with the softer will further contribute to reduce the number and severity of injuries. Anthropometric interior adjustment will also affect the reduction of injuries of passengers, as well as increasing comfort. Additionally, designers should pay special attention to the design of the bus interior, according to the abilities and capabilities of women's population over the age of 60 , because it is a particularly vulnerable population of users of city buses.

\section{Acknowledgements}

We wish to express our gratitude to the staff of the Clinical Center in Belgrade, who has given us the insight into the necessary documentation. This work is supported in a part by a grant from the Ministry of Science and Technological Development, Serbia.

\section{References}

[1] P. Albertsson and T. Falkmer, Is there a pattern in European bus and coach incidents? A literature analysis with special focus on injury causation and injury mechanisms, Accident Analysis and Prevention 37 (2005), 225-233.

[2] U. Bjornstig, P. Albertsson, J. Bjornstig, P-O Bylund, T. Falkmer and J. Petzall, Injury events among bus and coach occupants - non-crash injuries as important as crash injuries, IATSS Research 29 (2005), 79-87.

[3] R. Grant, A. Kirk and R. Bird, Why do passengers get hurt when buses don't crash?, in: Contemporary ergonomics 2002, P.T Mccabe, ed., Taylor \& Francis, London, 2002, pp. 465470.

[4] P. Halpern, M.I. Siebzehner, D. Aladgem, P. Sorkine and R. Bechar, Non-collision injuries in public buses: a national survey of a neglected problem. Emerg Med J 22 (2005), 108-110.

[5] A. Kirk, R. Grant and R. Bird, Passenger casualties in noncollision incidents on buses and coaches in Great Britain, in: Proceedings of the 18th International Technical Conference on the Enhanced Safety of Vehicles, US Department of Transportation, Nagoya (19-22 May).

[6] H. Nagata and S. Lee, Survey on accidental falls of elderly workers while commuting to and from work, in: Contemporary ergonomics 2004, P.T Mccabe, ed., CRC Press, Boca Raton, FL., 2004, pp. 78-82.

[7] A. Palacio, G. Tamburro, D. O’Neill and C.K. Simms, Noncollision injuries in urban buses - strategies for prevention, Accident analysis and prevention 41 (2009), 1-9.

[8] A.E. Wahlberg, Characteristics of low speed accidents with buses in public transport, Accident analysis and prevention 34 (2002), 637-647.

[9] A.E. Wahlberg, Characteristics of low speed accidents with buses in public transport: part II, Accident analysis and prevention 36 (2004), 63-71 